\title{
DECOY
}

\section{The score of a lifetime.}

\section{BY ERIC LEWIS}

$\mathrm{T}$ he two thieves stood before the giant vault, fresh out of ideas. "Well?" Braygin prodded, "what do you think?"

Tesca shrugged. "I think the Regent's not going to be pleased."

"The Regent's never pleased. When he hears about this he'll be furious." Two of the vault's magnetic locks hung open; those had been easy. But the third ... Braygin kicked a box of gear at their feet. "Are you sure you've tried everything, little man?"

"Everything! Electronic picks, lockout bypasses - even nanoexplosives didn't make a scratch. I've never seen a system this well guarded."

"Hmm. Guess that means we're in the right place," said Braygin, wiping a bead of sweat from the back of his neck. "Those rumours about Admiral Gnossi hiding her money in the gas oceans of Denovia must've been hogwash. But how do we get in there?"

Tesca fidgeted in his cumbersome spacesuit. "Whatever we do, it'd better be fast - security system comes back online in 15 minutes, and we'll need 5 of those to get back to the ship and blast off."

“Damn. To come so close!" Braygin slammed a fist against the plasteel face of the vault. He could almost taste the loot just out of reach. After months of bribing and snooping out the location of the asteroid base, they'd burgled deep inside to rob the Regent's biggest rival blind. Even a small share of whatever they stole could buy them each a small moon to retire on, but it seemed that the vault had defeated even Tesca's technocriminal talents. "There's absolutely nothing you haven't tried?"

"Nope, nothing. Erm, well ..."

"Erm, well what?"

Tesca looked away. "I wasn't gonna say anything - "

"Say it anyway!"

Tesca knelt and rooted through the box, tossing the various bits of equipment that'd failed them about the dim chamber. He rose holding an awkward, cobbled-together mass of wires and metal. An antimatter symbol emblazoned on the side screamed warning. "It's just a prototype..."

"A prototype what?"

"A portable spatial-displacement-field generator."

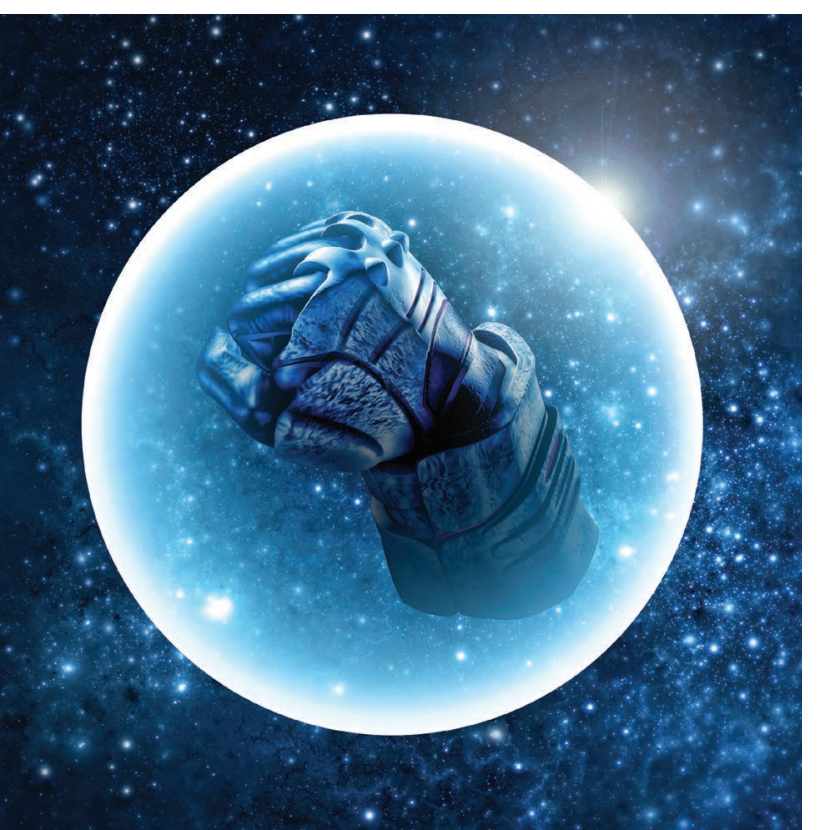

pretty simple. You set your field radius, set your displacement vector — say, three metres straight ahead for this door - then hit go. Only enough juice for a couple short jumps so we best go together ... there, all set." Tesca put the device down and went to retrieve his helmet - the atmosphere in the tunnels was thin but breathable and they'd quickly set the protective gear aside. "Better suit up all the way, just in case - oof?"

While Tesca's back was turned, Braygin shoved him hard, and the low-power grav plating sent him tumbling. Braygin grabbed the displacement device and caressed it greedily. "Sorry Tesca, like I said, this is the score of a lifetime, and I find I ain't willing to split it. Nothing personal; you'd do the same in my place if you had any brains for business. So long, little man!"

"No, Braygin, don't ...!" Tesca
"Spatial... what, like in the engines that move starships?"

"Well, technically, it's not the ship that moves, it's space itself _-"

"Whatever," said Braygin. "You mean you built a handheld version? Incredible! You could 'displace' us right through the door! Why didn't you start with that?"

"Like I said, it's a prototype ... also, the parts are highly illegal."

"Illegal? Tesca, we're breaking into Admiral Gnossi's vault. Just use the gadget so we can grab the cash and get outta here."

"But it's too dangerous! Without a full scan we've no idea what's on the other side. There could be guardbots, automated defences - "

Braygin clapped his partner on the shoulder. "Look, this is the score of a lifetime - I'll take the risk. Unless you want to be the one to bring the Regent the bad news?"

"... all right. Gimme a second to boot it up."

"Ten minutes and counting."

While Tesca worked the controls of the device, Braygin again eyed the great circular door, licking his lips with anticipation. "This is it. It's finally happening, after all these years. My big payoff. No more pennyante con jobs, no more rackets. No more bowing and scraping before thugs like the $\rightarrow$ NATURE.COM

Follow Futures: @ @NatureFutures

f go.nature.com/mtoodm back to Tesca. "Hey, how do you work that thing anyway?"

"Hmm? Oh, it's watched as Braygin was enveloped in a blue orb, then winked out of existence along with a little section of tunnel floor he'd been standing on. Tesca scrambled for his comm unit. "Braygin! Are you there? Braygin you lying cheat, talk to me!" Nothing.

After a few stunned seconds Tesca heard a low bang emanate from the vault door. From the other side it seemed. Then another, much weaker. Then silence. "Braygin?" He rummaged through his box of gear for a data pad and tried to patch into Braygin's suit camera. Although the signal was weak through the insulating plasteel, he managed to pick up an image, but no sound. The picture was rotating, slowly. He saw the other side of the door, then a wall of rock. A gloved fist drifted across the camera's field of view, and when it passed Tesca saw only a field of stars, stark against the blackness of open space.

"Huh," Tesca muttered to the empty chamber, glancing at Braygin's helmet left forgotten on the floor. "I guess Admiral Gnossi does keep her money on Denovia after all."

Tesca gathered up his most precious gear and scuttled back to the ship. No, the Regent was most definitely not going to be pleased.

Eric Lewis is an organic chemist still learning how to be a person again after surviving graduate school. His stories have appeared in Electric Spec, Bards and Sages Quarterly and other online venues. 